\title{
The protective effect of psychological suzhi on the relationship between school climate and alcohol use among Chinese adolescents
}

This article was published in the following Dove Press journal: Psychology Research and Behavior Management

\author{
Guang-Zeng Liu' \\ Yan-Gu Pan ${ }^{2}$ \\ Bing-Bing $\mathrm{Li}^{1}$ \\ Xiang-Ling $\mathrm{Hou}^{3}$ \\ Da-Jun Zhang'
}

'Faculty of Psychology, Research Center of Mental Health Education, Southwest University, Chongqing 4007I5, People's Republic of China; ${ }^{2}$ Research Institute of Social Development, Southwestern University of Finance and Economics, Chengdu 610052, People's Republic of China; ${ }^{3}$ School of Psychology and Cognitive Science, East China Normal University, Shanghai 200062, People's Republic of China
Correspondence: Da-Jun Zhang Faculty of Psychology, Research Center for Mental Health Education, Southwest University, No.2, Tiansheng Street, Beibei District, Chongqing 4007I5, People's Republic of China

$\mathrm{Tel}+8613509495486$

Fax +86 2368252376

Email zhangdj@swu.edu.cn
Background: There issome research on school climate impact on adolescent alcohol use in the Western social context; however, there is no research on school climate impact on adolescent alcohol use in China. This study aimed to explore the effect of school climate on Chinese adolescents' alcohol use, and the moderating role of psychological suzhi between them.

Methods: A total of 801 adolescents ( $45.8 \%$ boys, $14.96 \pm 1.66$ years) completed self-reports on school climate, psychological suzhi, and alcohol use.

Results: Moderation analyses revealed that both school climate and psychological suzhi significantly negatively predicted adolescents' alcohol use, and the interaction of school climate and psychological suzhi significantly positively predicted adolescents' alcohol use. Moreover, the effect of school climate on adolescents' alcohol use was stronger for low psychological suzhi adolescents than high psychological suzhi adolescents.

Conclusions: We can build good school climate by formulating of national level legal and regulations and good social norms, and use mature interventions or cultivation strategies to improve adolescents' psychological suzhi in order to better play its role in protection.

Keywords: school climate, psychological suzhi, alcohol use, adolescents

\section{Introduction}

Alcohol use is a high-risk behavior and is a widespread problem among adolescents, ${ }^{1}$ specifically in America where $80 \%$ of the students have consumed alcohol by the end of high school and $51 \%$ have done so by the eighth grade. ${ }^{2}$ Among 8,705 students aged 14-17 years from six European cities, the ageadjusted prevalence of weekly binge drinking and alcohol consumption was $4.2 \%$ and $11.3 \%$, respectively. ${ }^{3}$ In the selected eight Asian countries, over $15 \%$ of the total deaths among young men and 6\% among young women aged 15-29 years are attributable to alcohol use. ${ }^{4}$ China is a big consumer of alcoholic drinks, in view of the harm of alcohol use to national health, the government has adopted many measures in social propaganda and legal restrictions in order to reduce the consumption of alcohol, especially adolescents' alcohol use. For example, a high consumption tax is imposed on alcoholic products to raise their prices. At the same time, controlling alcohol use among adolescents is also an important part of school health work in China. Moreover, researcher used data from the national survey of adolescent health risk behaviors $(369,337$ secondary school students), which found that $70 \%$ of the senior high students had the 
history of alcohol use, and regarding gender differences, the prevalence of current drinkers was $36.4 \%$ and $23.8 \%$ and heavy binge drinkers was $3.3 \%$ and $1.2 \%$ for male and female students, respectively. ${ }^{5}$

Alcohol use has a detrimental effect on adolescents' physical, mental, and social development. ${ }^{1,6}$ Alcohol use could also be a predictor of academic achievement since students who use alcohol are less likely to attend class, complete their homework, achieve high marks, or value good grades. ${ }^{7}$ High alcohol consumption is also positively associated with anxiety and depression symptoms among adolescents and adults. ${ }^{8}$ McManama et al, ${ }^{9}$ found that increased frequency of alcohol use was associated with increased odds of a suicide attempt, and suggested that alcohol use may hasten the transition from suicidal ideation to suicide attempt in adolescents with low levels of depressed mood. In addition, alcohol may be a "gateway" substance that leads to the use of cannabis and other illicit drugs. $^{10}$

Hingson et al, ${ }^{11}$ found that the younger the age that people start drinking, the greater their likelihood of developing alcohol dependence within 10 years and before the age of 25 years and the stronger the subsequent association with chronic relapsing dependence, characterized by multiple episodes, past-year dependence, and, among dependent persons, episodes of longer duration and a wider range of symptoms. McGue et $\mathrm{al}^{12}$ also found that the age one started drinking was associated with a broad range of indicators of disinhibited behavior and psychopathology. Therefore, premature drinking can have a negative impact on an individual's future development.

In recent years, factors contributing to the development of adolescent alcohol use have been explored in order to create effective, efficient intervention strategies, and researcher found that family, school, and peers were closely associated with adolescents' alcohol use. ${ }^{13,14}$ The effect of schooling on students has long been of interest to educational researchers and policymakers. ${ }^{15}$ School climate refers to the quality and character of school life, which is based on patterns of people's experiences of school life and reflects norms, goals, values, interpersonal relationships, teaching and learning practices, and organizational structures. ${ }^{16}$ In recent years, there has been a growing body of research on the impact of student perceptions of school climate on their psychological, social, and academic adjustment. ${ }^{17}$

There are also some researches on how school climate impacts adolescent alcohol use. For example, in a longitudinal study with a sample of 2,490 German adolescents, class climate mediated a small, but significant part of the association between peer and adolescent alcohol use; ${ }^{18}$ Data from 15 year old students in Finland and Norway found that improved perceived school environment would reduce alcohol use. ${ }^{19}$ However, despite China's large population, there are relatively few studies on alcohol use, and due to distinct cultural factors, such as smoking and drinking tolerance, we cannot simply extend foreign research results in Chinese adolescents. ${ }^{20}$ Therefore, we explored if the school climate affects Chinese adolescents' alcohol use.

In addition, there are two kinds of measurement of school climate: objective and subjective. Objective measurement mainly occurs through the collection of school records, whereas subjective measurement mainly involves examining school members' perceptions on all aspects of the school climate. ${ }^{15,21}$ In contrast to the inadequacy of objective measurements, subjective measurement data can not only examine the perception of multi-party members, but also reflect the impact of school climate perception on individual's behavior. Therefore, in recent years, perception measurement has gradually become the main way for researchers to quantify school climate. ${ }^{21}$ Therefore, we employed a subjective instrument to test the adolescents' school climate.

In recent years, research has begun to focus on factors that affect adolescents' alcohol use in individual traits. ${ }^{22}$ Psychological suzhi, as a basic and core individual trait, participates in all aspects of psychological activities. Empirical researches have proved that psychological suzhi has an impact on the individual's internal psychological conditions and external behaviors, such as mental health, social adaptation, and academic development. ${ }^{23}$ Thus, we adopted psychological suzhi as the study variable.

Psychological suzhi is first proposed by Chinese scholars, which refers to a mental quality characterized by being steady, essential, and implicit. It has a derivative function and is closely related to individuals' developmental, adaptive, and creative behaviors, and is also a multi-level self-organized system that involves steady implicit mental qualities and explicit adaptive behaviors. ${ }^{24,25}$ Moreover, it has gained acceptance and recognition in Western academia. ${ }^{26}$ Quantitative (eg, questionnaire survey and factor analysis) and qualitative (eg, interviews and grounded theory) researches have verified that psychological suzhi has three dimensions: cognitive quality (including reflectivity, 
creativity, practice, and meta-cognition), individuality (including motive, emotion, will-power, and self), and adaptability (including self-orientation and society orientation). Cognitive quality can be manifested through an individual's cognitive processing and its connotation can be revealed through cognitive processing. As the most basic component of psychological suzhi, cognitive quality is involved directly in individuals' cognition on objects. Individuality can be reflected through individual's actions toward objects, while it is not involved directly in individuals' cognition on objects. However, as a core part of psychological suzhi, individuality has a motivation and moderating function during cognition. Adaptability component is individual's capabilities to arrive a consistency between themselves and the environment by changing themselves or the environment during the process of socialization; it is a component which can best reflect the derivative function of psychological suzhi. Overall, the three basic dimensions of psychological suzhi are interrelated and differentiated, which constitute the core elements of psychological suzhi. ${ }^{24,25}$

First, psychological suzhi can moderate the external environmental factors on the impact of individual positive and negative outcomes, such as depression, anxiety, and subjective well-being, typically as a protective effect. ${ }^{27}$ Second, according to the organism-environment interaction model, ${ }^{28}$ individuals with certain individual traits (eg, psychological suzhi) respond differently to similar environmental contexts, and not all individuals are equally influenced by the environment; dynamics of individual and context interactions contribute to the individual's psychological and social adaptation. Third, according to the risk-protective model, ${ }^{29}$ the strength of the relationship between risk and outcome will depend on the presence of protective factors, and the presence of protective factors weakens the relationship between risk and outcome. Consequently, psychological suzhi may serve as a protective moderator of the associations between school climate and adolescent alcohol use. Specifically, it may be explained that cognitive quality is directly related to the individual's perception of school climate. Individuality can play a motivation and moderating role in the process of perception of school climate, and adaptability can achieve a positive state of adaptation by changing adolescents themselves or school climate.

In sum, adolescent alcohol use is a universal phenomenon and its underlying mechanisms are worth studying, especially in China where these relationships have not been examined. Determining whether psychological suzhi moderates the associations between school climate and adolescents' alcohol use can help educators and administrators develop more effective management practices or interventions from the perspective of psychological suzhi. Therefore, we addressed the following hypotheses:

Hypothesis 1: School climate would be closely related to adolescents' alcohol use, low school climate may increase adolescents' alcohol use.

Hypothesis 2: Psychological suzhi would moderate the association between school climate and alcohol use. Specifically, the association between school climate and adolescents' alcohol use would be much weaker for adolescents with higher levels of psychological suzhi compared to those with lower levels.

\section{Methods}

\section{Participants and procedures}

Participants included 801 adolescents recruited from three secondary compulsory education schools in Southwest of China. We randomly selected 16 classes from 8 th to 9 th, and 11th to 12 th grade at the three schools $(201,313,287$ participants, respectively); the schools could represent other parts of China, and significant differences in gender and family setting were not found among the three schools or across grades. Two-hundred 53 participants were in eighth grade, 235 were in ninth grade, 164 were in eleventh grade, and 149 were in twelfth grade. Three-hundred 67 (45.8\%) were boys and 434 (54.2\%) girls. Participants were aged $11-19$ years $(M=14.96 \pm 1.66$ years $)$.

The Research Ethics Committee of Southwest University approved this study. We first achieved the school administrators' permission to conduct the survey. Written consent was then obtained from the class teachers of school and parents at the parents' meeting. The study surveyed 801 adolescents, who gave assent whose parents gave informed consent after explanation of the purpose and procedure of the study. All participants were tested during regular school hours in their classrooms. They were first instructed about the study purpose, and then administered the three questionnaires (school climate, psychological suzhi, and alcohol use) under the researchers' supervision, then handed the completed questionnaires to researchers.

\section{Measures \\ School climate}

Adolescent student perception of school climate was assessed with the Perceived School Climate Questionnaire 
developed by Bao et al, ${ }^{30}$ please see full details of the questionnaire in the Appendix. This scale contains six items, which were answered using a 4-point rating scale from 1 (never) to 4 (always). This scale is suitable for use with adolescents in the Chinese school environment, which is reliable among adolescents in China $(\alpha=0.85),{ }^{31}$ and it is also significantly correlated with the "Perceived School Atmosphere Questionnaire" as developed by Jia et al, ${ }^{17}$ ( $r=0.44, p<0.001)$, and the validity of the questionaire has been supported. ${ }^{32}$ In this study, we deleted the item "students at this school are often teased or picked on" because of low item-total correlation; responses across the rest five items were averaged after reverse scoring, with higher scores representing more positive perceptions of school climate, ${ }^{30}$ and Cronbach's alpha was 0.82 .

\section{Psychological suzhi}

We examined psychological suzhi using the Psychological Suzhi Questionnaire for Middle School Students, ${ }^{33}$ please see full details of the questionnaire in the Appendix. The questionnaire includes 24 items examining the following dimensions of psychological suzhi: cognitive quality, individuality, and adaptability, which were answered using a 5-point Likert-type scale from $1=$ totally disagree to $5=$ totally agree. Responses across the 24 items were averaged; higher scores indicate greater psychological suzhi. This questionnaire is suitable for adolescents in the Chinese school environment to use, and it is reliable among adolescents in China ( $\alpha=0.94$ for the total scale and ranged from 0.83 to 0.87 for the subscales). ${ }^{34}$ In this study, Cronbach's alpha of the total scale was 0.93 and ranged from 0.80 to 0.86 for the subscales.

\section{Alcohol use}

We assessed alcohol use using the Adolescents' Alcohol Use Questionnaire developed by Ye et al, ${ }^{35}$ which is suitable for use with adolescents in China. The questionnaire includes two items addressing alcohol use frequency (how many days have you been drinking in the past 30 days?) and alcohol use quantity (in the past 30 days, how many cups of beer do you drink every day?Cups: 4 cups of beer $=1$ bottle of beer $=50 \mathrm{~g}$ of liquor) each item. Alcohol use frequency is answered using a 6-point rating scale from 1 (never) to 6 (20-30 days), and alcohol use quantity is answered using a 6-point rating scale from 1 (never) to 6 (more than 10 cups). Responses across the two items were averaged, with higher scores representing more alcohol use. In this study, Cronbach's alpha was 0.82 .

\section{Analytic strategy}

The Statistical Package for Social Sciences (SPSS) Version 22.0 was used for data analyses. First, to investigate the general tendency of the measured variables, the mean and standard deviation for each variable, as well as the Pearson correlation coefficients between the variables, were analyzed. Next, since this study all used students' self-reports, it was not suitable to adopt multi-level modeling or hierarchical linear modeling. Thus, we used the PROCESS macro (http://www.alhayes.com) available for SPSS $^{36}$ to conduct moderation analyses. Concretely, we adopted Model 1 (especially for moderation analyses) to examine the moderating role of psychological suzhi on the relationship between school climate and alcohol use. We used 5,000 bootstrap samples, and biases were corrected at $95 \%$ confidence intervals (CI) to calculate the indirect effect of each variable. If the CI of the indirect effect did not include zero, then the indirect effect was significant at $p=0.05$. $^{37}$

\section{Results}

\section{Descriptive statistics among the variables}

Table 1 displays the gender differences for school climate, psychological suzhi, and alcohol use. Boys used alcohol significantly more than girls did. Table 2 displays the correlations prior to the moderation analysis. School climate was significantly positively correlated with psychological suzhi, and both of them were significantly negatively correlated with alcohol use. Additionally, we also computed the correlations between the three study variables and demographic variables (age and gender); only gender was significantly negatively correlated with alcohol use.

\section{Moderating role of psychological suzhi}

Table 3 shows the results of the moderation analysis performed to examine the moderating role of psychological suzhi between school climate and alcohol use after controlling for gender. School climate significantly negatively predicted alcohol use $(\beta=-0.139, p<0.001)$. Psychological suzhi significantly negatively predicted alcohol use $(\beta=-$ $0.167, p<0.001)$. Concurrently, the interaction of school climate and psychological suzhi significantly positively predicted alcohol use $(\beta=0.093, p<0.01)$. Therefore, psychological suzhi moderated the relationship between school climate and adolescents' alcohol use. To facilitate the interpretation of this moderating effect, Figure 1 
Table I Gender differences in school climate, psychological suzhi, and alcohol use

\begin{tabular}{|c|c|c|c|c|c|c|c|c|}
\hline \multirow[t]{2}{*}{ Variables } & \multicolumn{2}{|c|}{$\begin{array}{l}\text { Total } \\
(\mathrm{N}=\mathbf{8 0} \mathrm{I})\end{array}$} & \multicolumn{2}{|c|}{$\begin{array}{l}\text { Boys } \\
(n=367)\end{array}$} & \multicolumn{2}{|c|}{$\begin{array}{l}\text { Girls } \\
(n=434)\end{array}$} & \multirow[b]{2}{*}{$t$} & \multirow[b]{2}{*}{ d } \\
\hline & $M$ & $S D$ & $M$ & $S D$ & $M$ & $S D$ & & \\
\hline School climate & 2.23 & 0.73 & 2.20 & 0.73 & 2.26 & 0.72 & -1.23 & -0.09 \\
\hline Psychological suzhi & 3.46 & 0.58 & 3.44 & 0.62 & 3.47 & 0.55 & -0.75 & -0.05 \\
\hline Alcohol use & 1.26 & 0.73 & 1.39 & 0.90 & 1.16 & 0.52 & $4.29 * * *$ & 0.36 \\
\hline
\end{tabular}

Note: ${ }^{* * *} p<0.001$.

Table 2 Correlations between key variables

\begin{tabular}{|c|c|c|c|}
\hline Variables & $\begin{array}{l}\text { School } \\
\text { climate }\end{array}$ & $\begin{array}{l}\text { Psychological } \\
\text { suzhi }\end{array}$ & $\begin{array}{l}\text { Alcohol } \\
\text { use }\end{array}$ \\
\hline School climate & - & & \\
\hline $\begin{array}{l}\text { Psychological } \\
\text { suzhi }\end{array}$ & $0.12^{* *}$ & - & \\
\hline Alcohol use & $-0.16 * * *$ & $-0.19 * * *$ & - \\
\hline \multicolumn{4}{|c|}{ Correlations between observed covariates and study variables } \\
\hline Age & -0.05 & -0.02 & 0.00 \\
\hline Gender & 0.04 & 0.03 & $-0.16 * * *$ \\
\hline
\end{tabular}

Notes: $N=801$; $* * p<0.01, * * * p<0.001$.

Table 3 Standardized moderated model results

\begin{tabular}{|l|l|l|l|}
\hline $\begin{array}{l}\text { Dependent variable model for } \\
\text { predicting alcohol use }\end{array}$ & $\boldsymbol{\beta}$ & SE & $\begin{array}{l}\mathbf{9 5 \%} \\
\mathbf{C l}\end{array}$ \\
\hline School climate & - & 0.034 & - \\
& 0.139 & & $0.207,-$ \\
Psychological suzhi & - & 0.034 & - \\
& 0.167 & & $0.234,-$ \\
& & & 0.100 \\
School climate $\times$ Psychological suzhi & 0.093 & 0.031 & 0.032, \\
& & & 0.155 \\
\hline
\end{tabular}

presents the predicted alcohol use value as a function of school climate and psychological suzhi. Simple slope tests $^{38}$ revealed a no significant regression slope of school climate on alcohol use in the high psychological suzhi group ( $\beta=-0.046, p>0.05$ ). However, the effect of school climate on alcohol use was significant in the low psychological suzhi group $(\beta=-0.233, p<0.001)$. Namely, the effect of school climate on alcohol use was stronger for low psychological suzhi adolescents than for high psychological suzhi adolescents, which showed that the prediction effect of school climate on alcohol use was gradually weakened with the improvement of adolescents' psychological suzhi. Therefore, psychological suzhi served as a protective factor, reducing the potential risk of low school climate increasing adolescents' alcohol use.

\section{Discussion}

School climate was negatively associated with adolescents' alcohol use, and low school climate may increase alcohol use. This result supports Hypothesis 1. To our knowledge, this study is one of the first to confirm the impact of school climate on alcohol use among Chinese adolescents. A positive school climate was associated with lower alcohol use among adolescents, which was consistent with previous findings, ${ }^{18,19}$ which was also similar to Zhang et $\mathrm{al},{ }^{39}$ as they find that school climate can effectively predict Chinese adolescents' school adjustment. It is proved that low school climate may increase alcohol use in different social contexts, thus showing cross-cultural consistency.

As adolescents age, the main environmental factor gradual shifts from family to school, and individuals' close relationship with parents is gradually replaced by the ones with peers. ${ }^{40}$ This is especially true of many Chinese adolescent students who live at their school, especially for students from country, and their residence time generally lasts 6 years from seventh grade to 12th grade until the end of college entrance examination. Therefore, adolescents are most exposed to their teachers and peer classmates, the most familiar environment is their school. That is, teachers and peers play an important role in adolescents' psychology and behavior development. Jia et al, ${ }^{17}$ found that the perceptions of teacher support and peer support were positively associated with adolescents' self-esteem and grade point average, but negatively associated with depressive symptoms among both Chinese and American adolescents. These support systems may be related to alcohol use. When adolescents cannot perceive support from their teachers and peer of school climate, or perceive the vast academic pressure from their teachers, and this may one reason why they begin and keep alcohol 


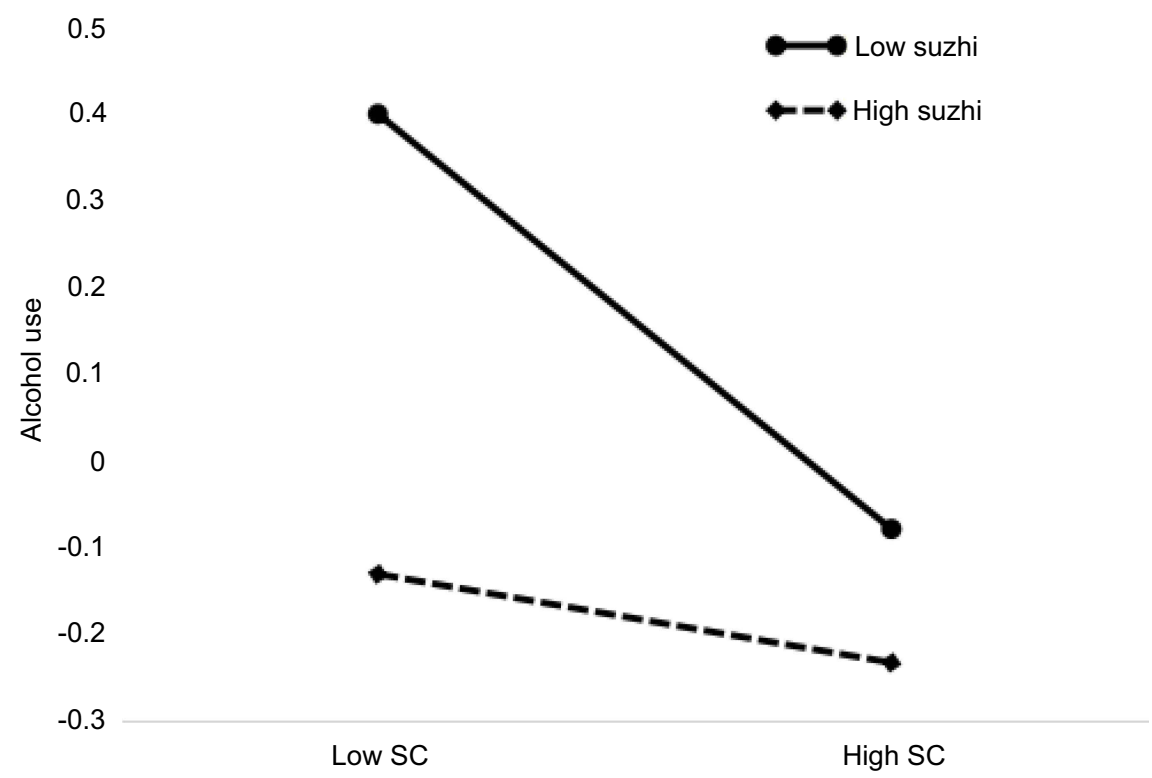

Figure I Psychological suzhi as a moderator on the relationship between school climate and alcohol use.

Abbreviations: SC, school climate; suzhi, psychological suzhi.

use; therefore, the support systems available on various campuses should be examined further. On the other hand, adolescents are easy to be influenced by their peer, as their peer are important risk factors to cause their alcohol use. ${ }^{41}$ This indicated us that we should try our best to create a good school climate (ie, teacher emotional warmth) to help reduce alcohol use.

Psychological suzhi moderated the association between school climate and alcohol use. Specifically, the association between school climate and alcohol use was much weaker for adolescents with higher levels of psychological suzhi. This result supports Hypothesis 2, and it also supports the psychological suzhi's function role, ${ }^{27}$ the organism-environment interaction model, ${ }^{28}$, and the risk-protective model. ${ }^{29}$ Psychological suzhi was negatively associated with adolescents' alcohol use, which was similar to Liu et $\mathrm{al}^{42}$ as they find that psychological suzhi negatively significantly predict adolescents' problem behaviors. High psychological suzhi adolescents generally display high cognitive quality and individuality (ie, the ability to accurately understand and respond to objects and form reasonable beliefs), and good adaptability (ie, the ability to effectively control their emotions and behavior). ${ }^{43}$ Thus, for adolescents in the school environment, higher psychological suzhi may lead to better internal regulation and coping in a wide range of life events, thereby reducing problem behaviors (eg, alcohol use).
School climate is an environmental factor, and psychological suzhi is an important part of individual traits, which as organism factor according to organism-environment interaction model. ${ }^{28}$ Individuals with certain individual traits (psychological suzhi in the current study) respond differently to similar environmental contexts (low school climate in the current study), and not all individuals are equally influenced by the environment. In the present study, adolescents who have high psychological suzhi were more likely to buffer the effect of low school climate on alcohol use, which was similar to Zhao et $\mathrm{al}^{44}$ as they find that high psychological suzhi buffers the effect of high peer victimization on adolescents' problem behaviors. Psychological suzhi as a protective factor, ${ }^{27}$ would weaken the relationship between risk (low school climate in the current study) and outcome (alcohol use in the current study), and play a decisive role between risk and outcome. ${ }^{29}$ The results indicated that when adolescents perceive a positive school climate, their alcohol use may decrease. Moreover, even when a school has a negative climate, it is possible for alcohol use to decrease if adolescents have elevated levels of psychological suzhi to protect themselves. On the basis of building a good school climate, it is probably more effective to pay more attention to improve the psychological suzhi of adolescents as we have mature interventions and cultivation strategies could help children and adolescents to cultivate their psychological suzhi. ${ }^{25}$ 
The current study has several strengths and practical implications. This was the first study to explicitly test the associations between school climate and alcohol use in adolescents who live in China and the moderating effect of psychological suzhi on the relationship between school climate and adolescents' alcohol use. The results indicated that both school climate and psychological suzhi could serve as protective factors for adolescents to reduce the potential risk. In order to protect adolescents' healthy physical, psychology, and social development by reducing alcohol use, we can build a good school climate by formulating of national level legal and regulations and good social norms. For example, changes to the minimum legal drinking age as well as in perceived social norms have been shown to contribute to decrease alcohol use in the United States; ${ }^{45}$ the Chinese government also explicitly stipulates that liquor operators are not allowed to sell alcoholic products to minors $(<18$ years old $)$. Additionally, we can also adopt effective and efficient intervention strategies to improve school climate. For example, previous research demonstrated that TEI Program, an intervention based on peer tutoring, is effective in reducing bully and cyberbully behavior, and at the same time, improving the school climate. ${ }^{46}$ Psychological suzhi could serve as a protective factor for adolescents to reduce the potential risk of low school climate for increased alcohol use. This indicated us we can pay more attention to cultivating and implement strategies for the development of adolescent psychological suzhi and in order to better play its role in protection. Adolescence is a key stage for psychological suzhi development, ${ }^{25}$ and there are many mature interventions or cultivation strategies to improve adolescents' psychological suzhi, such as special training mode and implementation strategies. ${ }^{25}$

Several limitations should be also noted highlight the need for cautious interpretation of our findings, and offer some guidance for future research. First, we used a crosssectional design; therefore, we cannot infer causal relationships between the examined variables. Future research should use a longitudinal or experimental design to test such possible relationships. Second, we used self-reported measures for all variables, it was not suitable to adopt multi-level modeling or hierarchical linear modeling to control student-level and school-level characteristics. Future research could use multiple methods, such as teacher reports to measure school climate. Lastly, we only examined alcohol use in schools, and people's attitudes toward alcohol use may differ in diverse contexts. ${ }^{20}$

\section{Conclusion}

We found that both school climate and psychological suzhi significantly negatively predicted adolescents' alcohol use, the interaction of school climate and psychological suzhi significantly positively predicted adolescents' alcohol use after controlling for gender, and the effect of school climate on adolescents' alcohol use was stronger for low as compared to high psychological suzhi adolescents. We demonstrated the key roles of school climate and psychological suzhi in reducing adolescents' alcohol use. Psychological suzhi served as a protective factor, reducing the potential risk of low school climate increasing adolescents' alcohol use.

\section{Acknowledgments}

This study has been supported by the Fundamental Research Funds for the Central Universities (SWU1809354). We thank all the participants in this study.

\section{Disclosure}

The authors report no conflicts of interest in this work.

\section{References}

1. Jessor R, Jessor SL. Problem Behavior Theory and Adolescent Health. Switzerland AG: Springer International Publishing; 2017.

2. Johnston LD, O'Malley PM, Bachman JG, et al. Monitoring the Future National Results on Adolescent Drug Use: Overview of Key Findings, 2012. Ann Arbor: Institute for Social Research, The University of Michigan; 2013.

3. Bosque-Prous M, Kuipers MA, Espelt A, et al. Adolescent alcohol use and parental and adolescent socioeconomic position in six European cities. BMC Public Health. 2017;17:646. doi:10.1186/s12889-0174635-7

4. Jiang $\mathrm{H}$, Xiang $\mathrm{X}$, Hao W, et al. Measuring and preventing alcohol use and related harm among young people in Asian countries: a thematic review. Glo Hea Res Pol. 2018;3(1):14. doi:10.1186/s41256-0180070-2

5. Ji CY. The prevalence of alcohol drinking among middle school students in China. Chin J Sch Health. 2010;31(10):1153-1156.

6. Catalano RF, Oesterle S, Fleming CB, Hawkins JD. The importance of bonding to school for healthy development: findings from the Social Development Research Group. J Sch Health. 2004;74(7):252-261.

7. Patte KA, Qian W, Leatherdale ST. Marijuana and alcohol use as predictors of academic achievement: a longitudinal analysis among youth in the COMPASS study. $J$ Sch Health. 2017;87(5):310-318. doi:10.1111/josh.12498

8. Knychala MA, Jorge MLMP, Muniz CK, et al. High-risk alcohol use and anxiety and depression symptoms in adolescents and adults with type 1 diabetes mellitus: a cross-sectional study. Diabetol Metab Syndr. 2015;7:24. doi:10.1186/s13098-015-0020-9

9. McManama KH, Becker SJ, Spirito A, et al. Differentiating adolescent suicide attempters from ideators: examining the interaction between depression severity and alcohol use. Suicide Life-Threat Behav. 2014;44(1):23-33. doi:10.1111/sltb.12050 
10. Degenhardt L, Dierker L, Chiu WT, et al. Evaluating the drug use "gateway" theory using cross-national data: consistency and associations of the order of initiation of drug use among participants in the WHO World Mental Health Surveys. Drug Alcohol Depend. 2010;108(1-2):84-97. doi:10.1016/j.drugalcdep.2009.12.001

11. Hingson RW, Heeren T, Winter MR. Age at drinking onset and alcohol dependence: age at onset, duration, and severity. Arch Pediatr Adolesc Med. 2006;160(7):739-746. doi:10.1001/archpedi.160.7.739

12. McGue M, Iacono WG, Legrand LN, et al. Origins and consequences of age at first drink. I. Associations with substance-use disorders, disinhibitory behavior and psychopathology, and P3 amplitude. Alcohol Clin Exp Res. 2001;25(8):1156-1165.

13. Goldberg-Looney LD, Sanchez-SanSegundo M, Ferrer-Cascales R, et al. Adolescent drinking in Spain: family relationship quality, rules, communication, and behaviors. Child Youth Serv Rev. 2015;58:236-343. doi:10.1016/j.childyouth.2015.09.022

14. Goldberg-Looney LD, Sanchez-SanSegundo M, Ferrer-Cascales R, et al. Adolescent alcohol use in Spain: connections with friends, school, and other delinquent behaviors. Front Psychol. 2016;7:269. doi:10.3389/fpsyg.2016.00269

15. Anderson CS. The search for school climate: a review of the research. Rev Educ Res. 1982;52(3):368-420. doi:10.3102/00346543052003368

16. Cohen J, McCabe L, Michelli NM, et al. School climate: research, policy, practice, and teacher education. Teach Col Rec. 2009;111 (1):180-213.

17. Jia Y, Way N, Ling G, et al. The influence of student perceptions of school climate on socioemotional and academic adjustment: a comparison of Chinese and American adolescents. Child Dev. 2009;80(5):1514-1530. doi:10.1111/j.1467-8624.2009.01348.x

18. Tomczyk S, Isensee B, Hanewinkel R. Moderation, mediation - or even both? School climate and the association between peer and adolescent alcohol use. Addict Behav. 2015;51:120-126. doi:10.1016/j.addbeh.2015.07.026

19. Samdal O, Wold B, Klepf KI, et al. Students' perception of school and their smoking and alcohol use: a cross-national study. Addict Res. 2000;8(2):141-167. doi:10.3109/16066350009004417

20. Wang Y, Zhang W, Li D, et al. Temperament and adolescent tobacco and alcohol use: a test of interaction effects. Psychol Dev Edu. 2012;28(3):292-300.

21. Zhang P, Li L, Xin T. Cross cultural comparison of linkage between school climate and students' mathematical achievement: a multilevel analysis. Psychol Dev Edu. 2011;27(6):625-632.

22. Bekman NM, Cummins K, Brown SA. Affective and personality risk and cognitive mediators of initial adolescent alcohol use. J Stud Alcohol Drugs. 2010;71(4):570-580.

23. Zhang DJ, Su ZQ, Wang XQ. Thirty-years study on the psychological suzhi of Chinese children and adolescents: review and prospect. Stud Psychol Behav. 2017;15(1):3-11.

24. Zhang DJ. On man's mental quality. Stud Psychol Behav. 2003;1 (2):143-146

25. Zhang DJ, Wang JL, Yu L. Methods and Implementary Strategies on Cultivating Students' Psychological Suzhi. New York, NY: Nova Science Publishers; 2011.

26. Furlong MJ, Gilman R, Huebner ES. Handbook of Positive Psychology in Schools. New York, NY: Taylor \& Francis; 2014.

27. Wang XQ, Zhang DJ. Looking beyond PTH and DFM: the relationship model between psychological suzhi and mental health. J Southwest Univ (Soc Sci Ed). 2012;38(6):67-74.

28. Lerner RM, Lerner JV, Almerigi J, et al. Dynamics of individual $\longleftrightarrow$ Context relations in human development: a developmental systems perspective. In: Thomas JC, Segal DL, Hersen M, et al. editors. Comprehensive Handbook of Personality and Psychopathology. Personality and Everyday Functioning. Vol. 1, Hoboken, NJ: John Wiley \& Sons Inc; 2006:23-43.
29. Hollister-Wagner GH, Foshee VA, Jackson C. Adolescent aggression: models of resiliency. J Appl Soc Psychol. 2001;31(3):445-466. doi:10.1111/j.1559-1816.2001.tb02050.x

30. Bao ZZ, Zhang W, Li DP, et al. School climate and academic achievement among adolescents: a moderated mediation model. Psychol Dev Edu. 2013;29(1):61-70.

31. Li D, Zhou Y, Li X, et al. Perceived school climate and adolescent Internet addiction: the mediating role of deviant peer affiliation and the moderating role of effortful control. Comput Hum Behav. 2016;60:54-61. doi:10.1016/j.chb.2016.02.015

32. Zhu J, Zhang W, Yu C, et al. School climate and pathological online game use among adolescents: the moderated mediation model. Psychol Dev Edu. 2015;31(2):246-256.

33. Hu TQ, Zhang DJ, Cheng G. Revision of the psychological suzhi questionnaire of the middle school students (simplified version) and the test of the reliability and validity. J Southwest Univ (Soc Sci Ed). 2017;10(3):120-126.

34. Liu G, Zhang D, Pan Y, et al. Self-concept clarity and subjective social status as mediators between psychological suzhi and social anxiety in Chinese adolescents. Pers Individ Differ. 2017;108:40-44. doi:10.1016/j.paid.2016.11.067

35. Ye B, Li D, Chen Q, et al. Sensation seeking and tobacco and alcohol use among adolescents: a mediated moderation model. Psychol Dev Edu. 2011;4:417-424.

36. Hayes AF. Introduction to Mediation, Moderation, and Conditional Process Analysis: A Regression-Based Approach. New York, NY: Guilford Press; 2013.

37. Shrout PE, Bolger N. Mediation in experimental and nonexperimental studies: new procedures and recommendations. Psychol Methods. 2002;7(4):422-445.

38. Dearing E, Hamilton LCV. Contemporary advances and classic advice for analyzing mediating and moderating variables. Monogr Soc Res Child Dev. 2006;71(3):88-104.

39. Zhang ZZ, Liang ZB, Deng HH, et al. Relations between perceptions of school climate and school adjustment of adolescents: a longitudinal study. Psychol Dev Edu. 2014;30(4):371-379.

40. Nickerson AB, Nagle RJ. Parent and peer attachment in late childhood and early adolescence. J Early Adolesc. 2005;25(2):223-249. doi: $10.1177 / 0272431604274174$

41. Pesola F, Shelton KH, Heron J, et al. The mediating role of deviant peers on the link between depressed mood and harmful drinking. J Adolesc Health. 2015;56(2):153-159. doi:10.1016/j. jadohealth.2014.10.268

42. Liu G, Zhang D, Pan Y, et al. The effect of psychological suzhi on problem behaviors in Chinese adolescents: the mediating role of subjective social status and self-esteem. Front Psychol. 2017;8:1490. doi:10.3389/fpsyg.2017.01490

43. Hu TQ, Zhang DJ. The relationship between psychological suzhi and depression of middle school students: the mediating role of self service attribution bias. J Southwest Univ (Soc Sci Ed). 2015;41 (6):104-109.

44. Zhao ZF, Liu GZ, Li SF, et al. Peer victimization and behavior problems in adolescence: mediation and moderation effects of psychological suzhi. J Southwest Univ (Soc Sci Ed). 2018;44 (5):90-97.

45. Patrick ME, Schulenberg JE. Prevalence and predictors of adolescent alcohol use and binge drinking in the United States. Alcohol ResCurr Rev. 2014;35(2):193-200.

46. Ferrer-Cascales R, Albaladejo-Blázquez N, Sánchez-SanSegundo $M$, et al. Effectiveness of the TEI program for bullying and cyberbullying reduction and school climate improvement. Int J Environ Res Public Health. 2015;16(4):580. doi:10.3390/ ijerph 16040580 


\section{Supplementary materials}

Perceived school climate questionnaire: 1 (never) to 4 (always).

1. Students at this school are often teased or picked on.

2. When students fight at school, teachers have no way to take control or do not intervene.

3. Students at this school smoke cigarettes or use alcohol.

4. Bullying or fighting is a problem of this school.

5. Cheating in school tests is a problem of this school.

6. Students at this school damage school property on purpose.

Psychological suzhi questionnaire: 1 (totally disagree) to 5 (totally agree).

1. I always have explicit pathways when doing exercises.

2. I always press myself to complete what I should do.

3. I am a popular person.

4. I can arrange and control my entertainment.

5. I am interested in new course content.

6. I keep good relationships with my teachers.
7. I usually do my things on my own.

8. I always do well in group activities.

9. I always set appropriate goals and plans of learning.

10. I can often effectively resolve the embarrassment.

11. When solving a problem, I usually have a sense of what kind of theorems and methods I have used.

12. I can face the frustrations in life bravely and never give up.

13. I can calmly response to the critical condition.

14. I never put off until tomorrow what I can do today.

15. I always build up associations between previous knowledge and the new.

16. In the learning process, I can timely initiative to adjust the way of learning.

17. I always adhere to my plan.

18. I get on well with my classmates.

19. I can solve problems by myself.

20. I can find a variety of resources to solve learning puzzles.

21. I can blend into my current surroundings.

22. I am always strict with myself.

23. I often organize or attend many class activities.

24. I can select appropriate methods based on tasks.

\section{Publish your work in this journal}

Psychology Research and Behavior Management is an international, peer-reviewed, open access journal focusing on the science of psychology and its application in behavior management to develop improved outcomes in the clinical, educational, sports and business arenas. Specific topics covered in the journal include: Neuroscience, memory and decision making; Behavior modification and management; Clinical applications; Business and sports performance management; Social and developmental studies; Animal studies. The manuscript management system is completely online and includes a very quick and fair peer-review system, which is all easy to use. Visit http://www. dovepress.com/testimonials.php to read real quotes from published authors. 